\title{
等 \\ TRANSPARÊNCIA DIGITAL NO PODER JUDICIÁRIO BRASILEIRO: UM PANORAMA DA APLICAÇÃ̃ DO ACESSO À INFORMAÇÃO NOS TRIBUNAIS DE JUSTIÇA
}

\author{
DIGITAL TRANSPARENCY IN BRAZILIAN JUDICIAL POWER: A PANORAMIC \\ APPLICATION OF ACCESS TO INFORMATION IN COURTS OF JUSTICE
}

\author{
TRANSPARENCIA DIGITAL EN EL PODER JUDICIAL BRASILEÑO: UNA \\ APLICACIÓN PANORÁMICA DE ACCESO A LA INFORMACIÓN EN LOS \\ TRIBUNALES DE JUSTICIA
}

\begin{abstract}
André Felipe Schlindwein ${ }^{1}$
Resumo: A transparência pode facilitar a abertura dos órgãos públicos, possibilitando o acesso à informação. Além dos poderes Executivo e Legislativo, o Judiciário também tem a responsabilidade por conferir transparência às suas atividades. Assim, o presente artigo busca verificar como a transparência é emprega da nos portais de três Tribunais de Justiça - SP, BA e MS. Para a coleta do material, propôs-se a navegação orientada. Desse modo, com o material coletado, o trabalho analisou a estrutura de acesso à informação disponibilizada nos três portais dos Tribunais de Justiça e verific ou as diferenças na aplicação da transparência ativa entre eles, considerando os seguintes aspectos: estrutura organizacional, programa e ações, divulgação das despesas, informações sobre licitações e contratos, além de questões judiciais. Verificou-se que os Tribunais de Justiça cumprem os requisitos básicos de transparência ativa. Além disso, cada um dos TJ possui peculiaridades na aplicação da transparência.
\end{abstract}

Palavra-chave: Democracia; Transparência Digital; Poder Judiciário

Abstract: Transparency can facilitate the opening of public agencies, allowing access to information. In addition to the Executive and Legislative powers, the Judiciary also has the responsibility for giving transparency to its activities. Thus, the present article seeks to verify how transparency is employed in the portals of three Courts of Justice - SP, BA and MS. For the collection of the material, guided navigation was proposed. Thus, with the materialcollected, the work analyzed the structure of access to information made a vailable in the three portals of the Courts of Justice and verified the differences in the application of active transparency between them, considering the following a spects: orga nizational structure, program and actions, disclosure expenses, information on bids and contracts, and legal issues. It was found that the Courts of Justice comply with the basic requirements of active transparency. In addition, each of the Courts has peculiarities in the application of transparency.

Keywords: Democracy; Digital Transparency; Judicial

Resumen: La transparencia puede facilitar la apertura de organismos públicos, permitiendo el acceso a la información. Además de los poderes Ejecutivo y Legislativo, el Poder Judicial también tiene la responsabilidad de proporcionartransparencia a sus actividades. Por lo tanto, este artículo busca verificar cómo se usa la transparencia en los portales de tres Tribunales de Justicia: SP, BA y MS. Para la recolección del material, se propuso la navegación guiada. Así, con el material recopilado, el trabajo analizó la estructura de acceso a la información disponible en los tres portales de los Tribunales de Justicia y verificó las diferencias en la aplicación de la transparencia activa entre ellos, considerando los siguientes a spectos: estructura organizacional, programa y acciones, divulgación de gastos, información sobre licitaciones y

${ }^{1}$ Mestre em Comunicação pela Universidade Federal do Paraná. E-mail: afschlindwein@ gmail.com. ORCID: 00000001-8599-1525 
contratos, y a suntos legales.. Se encontró que los Tribunales de Justicia cumplen con los requisitos básicos de transparencia activa. Además, cada uno de los TJ tiene peculiaridades en la aplicación de la transparencia.

Palabras clave: Democracia; Transparencia Digital; Poder Judicial.

\section{Introdução}

A transparência pode facilitar a abertura dos órgãos públicos, possibilitando o acesso à informação e, consequentemente, diminuir o monopólio do Estado sobre documentos oficiais, transformando-o em guardião de informações públicas (MICHENER; CONTRERAS; NISKIER, 2018), criando assim a transparência pública, ou seja, a transparência sobre a coisa pública, pertinente e de interesse público (ALMADA, 2017).

No caso brasileiro, existem diferentes mecanismos que foram criados visando o acesso às informações públicas e consequentemente à transparência. Além da Lei de Responsabilidade Fiscal, o Brasil também possui a chamada Lei de Acesso à Informação. Criada em 2011, a Lei 12.527 é um complemento regulatório ao Art. $5^{\circ}$ da Constituição de 1988 e foi criada como mecanismo de transparência pública, contemplando, como descrito em seu Art. $1^{\circ}$, “os órgãos públicos integrantes da administração direta dos Poderes Executivo, Legislativo e Judiciário (BRASIL, 2017, online, sem paginação).

Além dos poderes Executivo e Legislativo, o Judiciário também tem a responsabilidade de aplicar a transparência de suas atividades perante a sociedade, ou seja, o Poder Judiciário deve possuir uma gestão organizada e estruturada para desenvolver o acesso à informação (ANGÉLICO et al., 2017).

Assim, este artigo busca analisarcomo a transparência é aplicada nos Trib unais de Ju stiça A propostaé verificar como é feita a aplicação da transparência ativa nos portais de três Tribunais de Justiça, segmento esse que representa mais da metade das despesas, processos, magistrados e servidores do Poder Judiciário brasileiro. Tal fato mostra a importância dos Tribunais de Justiça dos Estados e reforça a importância e os desafios da aplicação da transparência no âmbito do Poder Judiciário.

A análise da transparência nos portais dos Tribunais de Justiça, proposta nesta investigação, faz-se relevante pela importância desse setor no Poder Judiciário. Os dados apresentados pela Justiça em Números, levantamento realizado pelo Conselho Nacional de Justiça, mostram que um dos maiores segmentos do Judiciário brasileiro é a Justiça Estadual, onde estão inseridos os Tribunais de Justiça - TJ.

Assim, os procedimentos e métodos que o artigo utilizou para a coleta e análise do material referente à transparência ativa, presente nos portais dos Tribunais de Justiça, como a navegação orientada as categorias doÍndice de Avaliaçãode Transparência Pública, desenvolvido pelo Programa de Transparência Pública da Fundação Getúlio Vargas.

$\mathrm{O}$ artigo está dividido em quatro partes. Na primeira parte é abordado o aspecto teórico 
da transparência e sua presença no Poder Judiciário. Na sequência é apresentada a seção metodológica de coleta e análise. Posteriormente, é apresentada a análise do material coletado e, por fim, são apresentadas as conclusões sobre a pesquisa.

\section{Poder Judiciário: Abertura e Transparência}

\subsection{A importância da transparência no Poder Judiciário}

Além dos poderes Executivo e Legislativo, o Judiciário também tem a responsabilidade de aplicar a transparência de suas atividades perante a sociedade, ou seja, o Poder Judiciário deve possuir uma gestão organizada e estruturada para desenvolver o acesso à informação (ANGÉLICO et al., 2017).

Como bem lembram Bochenek, Dalazoana e Rissetti (2013), a administração responsável e a fiscalização dos recursos públicos também são necessárias no Poder Judiciário. Porém, como destacam Hoch, Rigui e Silva (2013), é importante que as informações disponibilizadas pelo Poder Judiciário aconteçam de forma ativa:

Com a aplicação da transparência no Judiciário, é possível combater a percepção de ineficiência do Judiciário em ações cotidianas (FRAGALE FILHO, 2011; BOCHENEK, DALAZOANA, RISSETTI, 2013), “Além disso, com a implantação efetiva da transparência talvez seja possível esclarecer ou encontrar pistas sobre o mito da morosidade e da lentidão que envolvem o Poder Judiciário" (BOCHENEK, DALAZOANA, RISSETTI, 2013, p. 542)

De tal modo, através das ferramentas digitais, é possível acompanhar, por exemplo, o andamento de processos e outras informações ligadas ao Judiciário, ou até mesmo entrar em contato com o Poder para reportar dúvidas ou reclamações. Assim, o acesso a esse tipo de informação relaciona-se com o acesso à Justiça (OLIVEIRA; DINARTE, 2015, p. 287).

Entretanto, é necessário que essas ferramentas sejam aplicadas pelo Poder Judiciário. É preciso que os tribunais criem uma estrutura que além de apresentar as informações, seja de fácil compreensão para o cidadão. Além disso, é necessária a divulgação dessas ferramentas para que o público as conheça e as utilize, de fato. Afinal, se os mecanismos que promov em a transparência forem aplicados de forma precária e sem publicidade, mesmo com o ambiente digital, teremos uma transparência pouco efetiva.

Elena, Aquilino e Riviére (2014) defendem que a transparência no Poder Judiciário deveria ser um comportamento padrão. O argumento para essa postura é o de que o Judiciário presta um serviço público que afeta o cotidiano do cidadão, portanto, deveria prestar esclarecimentos. Como apontado por Michener (2016), a aplicação da transparência no Judiciário pode auxiliar na legitimidade da independência conferida a essa esfera de poder

É importante destacar que uma maior abertura do Poder Judiciário não significa que pilares como a independência (VOERMANS, 2007) serão prejudicados, pelo contrário, com a aplicação da transparência no Poder Judiciário é possível aproximar esse setor da sociedade, 
publicizando e tornando acessível o acompanhamento de seu funcionamento e da tomada de decisões. Fragale Filho (2011) sugere que através desse acompanhamento, a sociedade atuaria como inspetora das ações realizadas pelos tribunais, ou seja, fortalecendo a democracia e o controle social.

Steytler (2005) explica que os fundamentos para a integridade judicial, e que são essenciais para o funcionamento de uma democracia, são a independência, a imparcialidade, a responsabilidade e a transparência e: "Quando qualquer um deles é minado por falhas institucionais, o governo honesto, aberto e responsável é colocado em risco" (STEYTLER, 2005, p. 1).

Porém, muitas vezes, a independência acaba afastando o Judiciário da sociedade por uma postura fechada (OLIVEIRA; DINARTE, 2015, p. 278). Um exemplode mecanismo paraa busca da independência do Judiciário é que diferentemente dos poderes Executivo e Legislativo, os membros do Poder Judiciário não são escolhidos ou af astados através de um processo eleitoral (MICHENER, 2016).

Entretanto, é importante lembrar que a não eleição de magistrados é necessária para uma maior independência de juízes. Porém, isso acaba criando perigos, como a possível formação de grupos de interesses ou umaautonomia que faça o Poder Judiciário não prestar contas à sociedade.

Voermans (2007) afirma que o Judiciário não pode mais ser protegido com a alegação da independência do controle e responsabilidade pública. Assim, é necessário que sejam criadas ferramentas para a aplicação da transparência nessa esfera de poder. Assim, essa "é uma das soluções para esse problema e uma ferramenta fundamental para assegurar a legitimidade da própria independência conferida ao Poder Judiciário"(MICHENER, 2016, p. 77).

Portanto, a transparência pode colaborar na legitimidade das ações, através da abertura e de uma maior eficiência da Justiça. Desse modo, "Legitimidade do Estado e, portanto, também do Judiciário, é baseada em uma mistura de ingredientes: responsabilidade, representatividade, legalidade e transparência" (VELICOGNA, 2006, p. 375). Tal eficiência e abertura estão ocorrendo por meio dos meios eletrônicos, com iniciativas de governo eletrônico.

Entretanto, como apontado em estudo realizado por Elena, Aquilino e Riviére (2014), o Judiciário na América Latina, apesar do progresso, é um dos menos dispostos a implementar políticas de transparência e de dados abertos. Se utilizada, a abertura de dados pode, além da transparência, melhorar a eficiência do sistema judicial (ELENA; AQUILINO; RIVIÉRE, 2014) e aproximar essa esfera de poder da sociedade (OLVEIRA; DINARTE, 2015).

Porém, como defendem Steytler (2005) e Fragale Filho (2011), a transparência não é apenas a simples disponibilização de dados ao público. É necessário que se faça compreender quais as funções exercidas nos tribunais e o porquê delas. Ou seja, não adianta o acesso à informação relacionada a processos, como tempo de tramitação, se o cidadão não tiver conhecimento dos procedimentos do tribunal. 


\subsection{A aplicação da transparência através das ferramentas digitais}

A questão da transparência passou a ter maior destaque graças ao surgimento dos meios online (MICHENER; BERSCH, 2013). Com a internet, as informações passaram a ser mais visíveis, graças à oferta de ferramentas e possibilidades para projetos e iniciativas que têm como objetivo a produção da transparência (ALMADA, 2017).

Meijer (2009) cita que a transparência nos meios digitais auxilia no aperfeiçoamento do combate à corrupção pelos governos ao redor do mundo. $\mathrm{O}$ autor explica que os defensores da transparência mediada pelos dispositivos digitais argumentam que ela proporciona maior informação ao cidadão, além de contribuir para a racionalização coletiva, resultando em uma sociedade mais democrática. Já os opositores argumentam que uma transparência unidirecional, estruturada e descontextualizada resulta em uma perda de confiança social (MEIJER, 2009).

Ambos os pontos são pertinentes. As ferramentas digitais proporcionam o desenvolvimento de mecanismos de transparência muito mais sofisticados, além de fornecerem o acesso às informações virtualmente, sem a necessidade do cidadão se deslocar até uma instituição pública. Porém, o ambiente digital não soluciona todosos problemas de transparência, ainda pode existir opacidade, como a omissão ou alteração de informações, além da oferta de péssimas estruturas para a navegação, dificultando a busca por informações.

Para a efetividade da transparência digital nas instituições, Silva (2009, p. 49) aponta que, além de informações pertinentes, é preciso utilizar "as novas tecnologias para divulgar, informar, esclarecer, justificar e debater com o público de forma regular”. Tais fatos podem colaborar com a formação da opinião pública e a participação cidadã (TAVARES; PEREIRA, 2011). Essas características, segundo os autores, passam por grandes mudanças nos meios de comunicação online.

Dessa forma, com as mudanças na comunicação proporcionadas pelo ambiente online, os órgãos do Estado precisaram se adaptar e passar a utilizar as ferramentas disponíveis no ambiente digital para se aproximar da sociedade (ALMADA, 2017). São exemplos sites e portais, bem como perfis em redes sociais digitais.

Assim, podemos abordar algumas das características das plataformas digitais, incluindo sua importância em processos sociais voltados à produção da transparência (HANSEN; FLYVERBOM, 2015). Os autores afirmam que, geralmente, dispositivos de divulgação são aplicados para tornar objetos, sujeitos e processos visíveis através de representações visuais, verbais e numéricas. Nesse caso, as representações que resultam da divulgação não estão apenas determinadas em classificações institucionais e seleções feitas no processo de produção, mas também na tradução de conhecimento e relacionamentos locais em novos contextos e domínios, e reduzindo ou até potencialmente até ocultando, a complexidade do que as representações tinham como objetivo tornar legível em primeiro lugar.

Assim, as iniciativas de transparência digital têm provocado mudanças na maneira como 
as instituições públicas estão utilizando o ambiente online para a produção de transparência (ALMADA, 2017). A ideia é a de que seja feita uma boa transparência, com acesso irrestrito às informações por meio de plataformas e aplicativos ou portais que sejam de fácil manuseio e compreensão do cidadão. (GOMES; AMORIM; ALMADA, 2018).

\subsubsection{As tecnologias digitais como facilitadoras da transparência no Poder Judiciário}

Através das ferramentas digitais é possível que os órgãos públicos, como o Poder Judiciário, apliquem a transparência bem como o acesso a processos, práticas que acabam por melhorar a acessibilidade da informação pública e a qualidade da comunicação entre os cidadãos e o governo (KIŠKIS; PETRAUSKAS, 2004).

Os autores destacam que as Tecnologias de Informação e Comunicação - TIC podem ser utilizadas como ferramentas para uma abertura e a maior transparência do Judiciário e, consequentemente, colaborar para a legitimidade desse Poder (VELICOGNA, 2006), e o desenvolvimento democrático. Além disso, as ferramentas digitais podem auxiliar não apenas na temática da transparência, mas também facilitar os procedimentos administrativos dessa esfera, agilizando processos, julgamentos e consultas.

Outro ponto benéfico das ferramentas digitais é que, com a digitalização de vários aspectos da administração, são possíveis a catalogação e a indexação de informações, possibilitando assim o surgimento de ambientes virtuais de controle e consulta de dados (KIŠKIS; PETRAUSKAS, 2004). Para essas práticas, o Judiciário tem se aperfeiçoado, criando ferramentas que colaborem com a interação entre os tribunais e a sociedade (PÍTSICA, 2012). São exemplos a criação de ouvidorias e de portais voltados ao cidadão, em que podem ser encontrados mecanismos para a disponibilização de documentos, processos, pareceres e resultados de votações.

Além das questões já mencionadas, as ferramentas digitais também podem auxiliar na legitimação da independência do Poder Judiciário. As informações disponibilizadas, bem como o fácil acesso a defesa judicial, são itens que colaboram para a maior aproximação desse Poder com a sociedade civil. (KIŠKIS; PETRAUSKAS, 2004).

Podemos verificar diferentes formas de aplicação da transparência no Poder Judiciário através dos estudos apresentados por Michener et al. (2016), Elena, Aquilino e Riviére (2014), Steytler (2005) e Velicogna (2006). O primeiro aborda o tema em âmbito nacional, o segundo é focadona América Latina, enquanto o terceiro trata da questão no Judiciário australiano o quarto compara a estrutura de acesso à informação em tribunais dos Estados Unidos, Holanda e Itália.

A pesquisa de Michener et al. (2016) tem o objetivo de oferecer um levantamento do cumprimento da Lei de Acesso à Informação nos tribunais brasileiros. A pesquisa mostra que a taxa de resposta a pedidos de informação pelo Poder Judiciário demora em média 12 dias. Além 
disso, a avaliação mostra que a divulgação de informações referentes a orçamento, finanças, quadro de pessoal e remuneração sofre diferentes interpretações, "de forma a eximir os tribunais de responder a pedidos de acesso à informação sobre outros dados não contemplados na resolução" (MICHENER, 2016, pp. 130-131).

Estes fatos apontampara uma conduta contráriaà dos tribunais referentes à Lei de Acesso à Informação, afinal, a norma busca padronizar a apresentação das inf ormações, para melhor entendimento e comparação, beneficiando a eficácia do controle social sobre os gastos públicos (MICHENER, 2016).

Outro estudo que avalia as políticas de transparência no Poder Judiciário é o de Elena, Aquilino e Riviére (2014), que foca no impacto causado pela política de dados abertos no Poder Judiciário, mais especificamente no Judiciário da Argentina, Chile e Uruguai. A pesquisa das autoras constata que não existe uma política de dados abertos nos Judiciários argentino, chileno e uruguaio, embora exista um ambiente adequado para o acesso de dados.

O estudo destaca que mesmo com a falta de uma política de dados abertos nos judiciários estudados, existe a implementação de políticas abrangentes de publicação de informações, caracterizadas pela acessibilidade e não descriminação. Porém, os dados compartilhados não possuem formatos livres, necessitando de softwares licenciados, dificultando a circulação do material pelos usuários.

Já na pesquisa de Steytler (2005), é possível perceber a bu sca pela transparência do Judiciário australiano com a criação da Conferência Judicial da Austrália, que busca auxiliar na prestação de informações para a mídia. "Esse órgão, que obteve grande sucesso em sua tarefa, supera, até certo ponto, a dificuldade decorrente do desaconselhamento de juízes individuais que se manifestam publicamente sobre questões que lhes dizem respeito" (STEYTLER, 2005, p. 9). Além disso, os tribunais da Austrália publicam relatórios anuais com informações e estatísticas sobre número de processos e atrasos.

Por último, o estudo de Velicogna (2006) tem o objetivo de examinar se o acesso a informações referentes ao Judiciário, como atividades dos tribunais e casos disponíveis virtualmente, pode aumentar a legitimidade do Poder Judiciário. Assim, o autor verificou os sites de tribunais italianos, da Holanda e dos tribunais do estado de Nova York nos Estados Unidos.

Sobre o Judiciário italiano, Velicogna (2006) aponta para um baixo esforço na implementação de ferramentas nos sites, incapacitando o acesso claro ao público. O autor classifica o esforço exercido pelo Judiciário italiano como amador, salvo algumas experiências como a do Supremo Tribunal de Cassação, do Tribunal de Trieste, dos tribunais administrativos e dos tribunais da Sicília.

Em comparação, a análise dos tribunais da Holanda e de Nova York (VELICOGNA, 2006) mostrou resultados positivos, contrapondo-se ao caso italiano. A principal característica dos sites holandeses é apresentar uma imagem coerente de um sistema Judiciário mais aberto ao 
cidadão, unificando sua imagem e proporcionando acessoàs suas atividades. Já no site do Sistema Unificado de Tribunais do Estado de Nova York, as informações, dados e ferramentas dos tribunais estão integrados no portal, proporcionando fácil acesso ao cidadão.

Assim, os estudos aqui apresentados mostram diferentes formas de disponibilização do acesso à informação em diferentes sistemas do Judiciário, além de apontar seus êxitos e suas falhas. Isso mostra que não existe apenas uma maneira de implementação da tran sparência no ambiente online, que necessita ser bem planejada e estruturada para alcançar o público.

Portanto, é possível verificar como os meios digitais podem colaborar com às políticas de acesso à informação, desse modo, fortalecendo a transparência no setor público, tornando a administração mais eficiente.

\section{Procedimentos Metodológicos}

Para a análise, foi selecionado um corpus composto por três Tribunais de Justiça. A escolha foi realizada com base na divisão realizada pelo $\mathrm{CNJ}^{2}$ em três diferentes portes de Tribunal: grande (cinco Tribunais), médio (dez Tribunais) e pequeno (doze Tribunais). Tal divisão é feita com base no total de despesas, número de processos, número de magistrados e número de servidores de cada Tribunal.

Para chegar ao número de três TJ, foi selecionado o Tribunal de cada porte com maior orçamento, permitindo verificar estruturas com orçamentos diferentes. Além disso, o volume de recursos financeiros disponibilizado pode influenciar na oferta de acesso à informação nos sites dos Tribunais de Justiça. Afinal, a aplicação da transparência necessita de recursos financeiros para ser colocada em prática.

Assim, os Tribunais de Justiça selecionados foram: TJ-SP (grande porte); TJ-BA (médio porte) e TJ-MS (pequeno porte). A tabela apresentada abaixo mostra os dados que colaboraram para a seleção dos Tribunais de Justiça mencionados. Ela corresponde aos dados coletados pelo Conselho Nacional de Justiça no ano de 2017 e apresentados no relatório Justiça em Números 2018, a exceção são as informações referentes ao orçamento, disponibilizadas à parte pelo CNJ.

\footnotetext{
${ }^{2}$ CNJ. Justiça em Números 2018: ano-base 2017, Conselho Nacional de Justiça - Brasília, 2017.
} 
Tabela 1 - Tribunais de Justiça Selecionados

\begin{tabular}{|c|c|c|c|c|c|c|c|c|c|}
\hline TRIBUNAL & Escore & Despesa Total & $\begin{array}{l}\text { Casos } \\
\text { Novos }\end{array}$ & $\begin{array}{l}\text { Casos } \\
\text { Pendentes }\end{array}$ & Magistrados & $\begin{array}{l}\text { Servidores e } \\
\text { Auxiliares }\end{array}$ & $\begin{array}{l}\text { Orçamento } \\
\text { Geral }\end{array}$ & $\begin{array}{l}\text { Total Judiciário } \\
\text { Estadual }\end{array}$ & $\begin{array}{l}\% \text { do JUDIC. no } \\
\text { ORÇAM. } \\
\text { ESTADUAL }\end{array}$ \\
\hline \multicolumn{10}{|l|}{$\begin{array}{l}\text { GRANDE } \\
\text { PORTE }\end{array}$} \\
\hline TJ - São Paulo & 4,333 & 11.830 .621 .214 & 5.648 .114 & 20.591 .965 & 2.651 & 68.676 & 206.399.953.232 & 10.839 .544 .597 & 5,25 \\
\hline \multicolumn{10}{|l|}{$\begin{array}{l}\text { MÉDIO } \\
\text { PORTE }\end{array}$} \\
\hline TJ - Bahia & 0,301 & 3.597 .816 .383 & 1.028 .967 & 2.811 .404 & 585 & 12.947 & 43.772 .584 .633 & 2.311 .335 .000 & 5,28 \\
\hline \multicolumn{10}{|l|}{$\begin{array}{l}\text { PEQUENO } \\
\text { PORTE }\end{array}$} \\
\hline $\begin{array}{l}\text { TJ - Mato } \\
\text { Grosso do Sul }\end{array}$ & $-0,400$ & 977.542 .271 & 344.795 & 889.979 & 215 & 5.374 & 13.991 .974 .000 & 848.282 .500 & 6,06 \\
\hline
\end{tabular}

Fonte: CNJ (2018)

Os dados apontam as despesas totais que cada tribunal teve em 2017, bem como novos casos e casos pendentes de responsabilidade de cada TJ. A tabela também apresenta o número de funcionários dos tribunais, incluindo magistrados, servidores e auxiliares. Esses dados formam um escore que o CNJ calcula para a separação de cada Tribunal de Justiça por porte. A tabela também apresenta o orçamento total de cada estado, o valor que é destinado aos tribunais e qual é a porcentagem desse valor perante o orçamento estadual. Essas informações colaboram para compreender a estrutura dos Tribunais de Justiça, desde seu tamanho em volume de processos e de funcionários até o orçamento disponibilizado, influenciando na maneira como cada TJ se organiza estruturalmente.

Para a coleta do material relacionado à transparência, presente nos sites dos Tribunais de Justiça mencionados, propõe-se o método utilizado por Almada (2013; 2017) e Amorim (2012).

Em seu estudo sobre o acesso à informação no portal das prefeituras de cada capital brasileira, Amorim (2012) relatou que a coleta dos dados foi realizada através da navegação orientada, utilizando uma base de instrumento construída por subsídios classificados em três aspectos essenciais. São eles: informações gerais, informações e serviços técnicos e informações e serviços específicos. No caso do estudo aqui apresentado, foram considerados os seguintes aspectos relacionados aos Tribunais de Justiça: estrutura organizacional, programa e ações, divulgação das despesas, informações sobre licitações e contratos, além de questões judiciais. Almada (2017) também realizou a coleta dos dados através da navegação orientada nos portais do Governo Federal dos países que analisou em sua pesquisa.

Por meio desse tipo de navegação, foi estipuladaa forma de transitar pelos links e páginas, assim como os critérios e parâmetros para qualificar os objetos catalogados na navegação, conforme as categorias validadas e estabelecidas na etapa da pesquisa exploratória. 
Assim, o trabalho aqui apresentado, localizou os conteúdos referentes à transparência, realizando uma navegação a partir da página principal de cada Tribunal de Justiça, buscando links que levem até conteúdos ligados à transparência. Assim, comparando o conteúdo coletado em cada Tribunal de Justiça.

Almada (2017) explica que através da pesquisa comparada, é possível chegar ao objetivo da pesquisa é compreender o nível de transparência do governo federal brasileiro e "a partir daí identificar em quais aspectos o Brasil precisa melhorar ou aprimorar o modo de utilização do digital para se tornar mais transparente e aberto aos cidadãos (ALMADA, 2017, p. 163).

Portanto, as páginas relacionadas ao tema da transparência nos portais dos tribunais foram navegadas e catalogadas pelo autor entre os dias 4 de setembro e 9 de novembro de 2018 para verificar como é aplicada à transparência presentes em cada tribunal.

Através desses procedimentos, a pesquisa verificou como os Tribunais de Justiça $\mathrm{a}^{3}$ usam as ferramentas online para o emprego da transparência ativa em seus sites. A análise foi dividida em cinco categorias, conforme estabelecido pelo Índice de Avaliação de Transparência Pública, desenvolvidopelo Programa de Transparência Pública da Fundação Getúlio Vargas(FGV, 2018).

\section{Aplicação da Transparência nos sites dos Tribunais de Justiça}

Nesta sessão, apresentaremos os dados e a análise do material coletado nos Tribunais de Justiça selecionados, bem como a discussão dos dados. A sessão está dividida em seis partes, as cinco primeiras referentes às variáveis analisadas: Estrutura Organizacional, Programas e Ações, Despesas, Licitações e Contratos, e Questões Judiciais e a última relacionada à discussão dos dados.

\subsection{Estrutura organizacional}

$\mathrm{O}$ item estrutura organizacional é relacionado a informações sobre a estrutura do órgão (organograma, lista de cargos e setores ou semelhante). Além disso, deve existir informações sobre endereço, telefone e horário de funcionamento da instituição presentes no site de cada um dos Tribunais.

Representante dos Tribunais de Justiça de grande porte, o TJ-SP cumpre quase a totalidade dos itens. O TJ-SP disponibiliza no rodapé de seu site as informações referentes ao endereço e telefone, porém não informa o horário de atendimento. Sua estrutura não foi encontrada em um organograma, porém o TJ disponibiliza as informações de setores e cargos no item Institucional, em sua barra de menu.

3 Tribunais de São Paulo, Bahia e Mato Grosso do Sul. 
Figura 1 - Informações TJ-SP

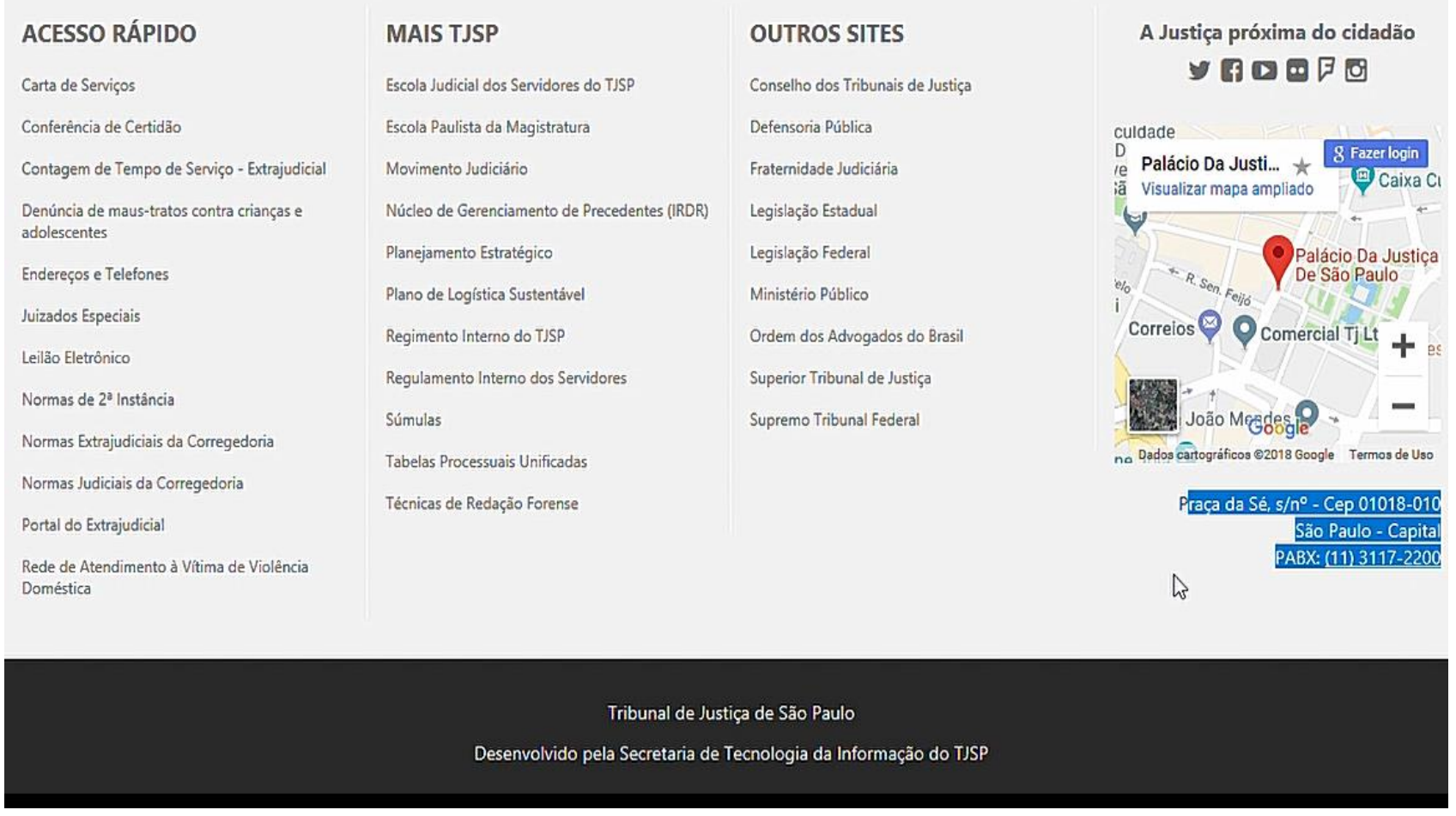

Fonte: TRIBUNAL de Justiça do Estado de São Paulo. Disponível em: http://www.tjsp.jus.br/. Acesso em 9 nov. 2018.

Já na categoria dos TJ de médio porte, o Tribunal de Justiça da Bahia também apresenta as informações de endereço e telefone. Os dados sobre o organograma da instituição podem ser acessados através de um link denominado Estrutura Organizacional, disponível no rodapé do site.

Figura 2 - informações TJ-BA

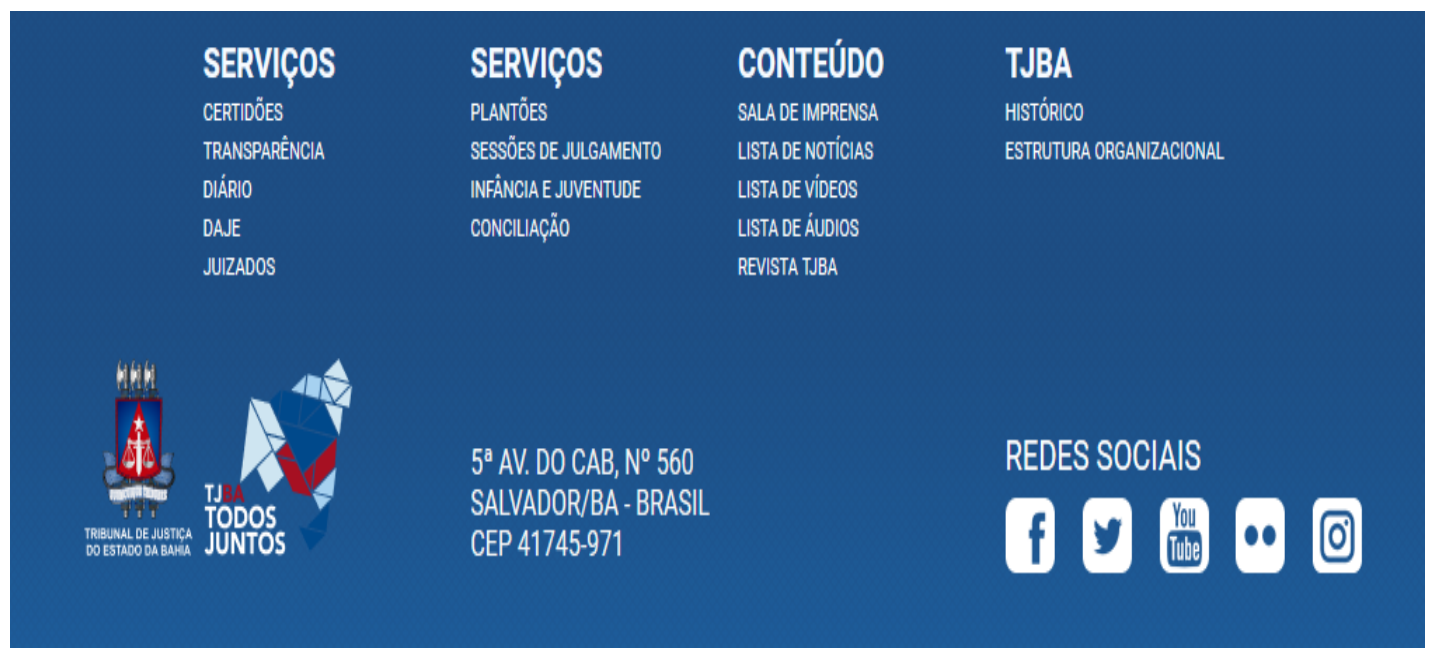

Fonte: TRIBUNAL de Justiça do Estado da Bahia. Disponível em: http://www5.tjba.jus.br/portal/. Acesso em 22 out. 2018 . 
Por último, o TJ do Mato Grosso do Sul, categorizado como de pequeno porte. O Tribunal cumpre integralmente os itens avaliados. Todas as informações de atendimento e o endereço podem ser encontrados ao final da página. Para acessar o organograma, basta acessar a aba Institucional no menu e clicar no link Estrutura Organizacional.

Figura 3 - informações TJ-MS 1

\section{Copyright @ 2013 TJ-MS - Av. Mato Grosso - Bloco 13 - Fone: (67) 3314-1300 - Parque dos Poderes - 79031-902 - Campo Grande - MS Fórum de Campo Grande - Fone: (67) 3317-3300 / CIUUS - Centro Integrado de Justiça - Fone: (67) 3317-8600 Horário de Expediente: $12 \mathrm{~h}$ às $19 \mathrm{~h}$.}

Fonte: TRIBUNAL de Justiça do Estado de Mato Grosso do Sul. Disponível em: http://www.tjms.jus.br/. Acesso em 9 nov. 2018.

Figura 4 - informações TJ-MS 2



Fonte: TRIBUNAL de Justiça do Estado de Mato Grosso do Sul. Disponível em: http://www.tjms.jus.br/organograma/imagens/00_base.png. Acesso em 9 nov. 2018. 


\subsection{Programas e ações}

No que se refere a esta dimensão, o tribunal deve apresentar informações relacionadas a programas e ações desenvolvidas pela instituição. Assim, deve existir uma página destinada ao tema, uma lista de atividades desenvolvidas, a descrição dos programas, além de informações sobre as atividades realizadas.

Iniciando pelo Tribunal de Justiça de grande porte, o TJ-SP, a categoria pode ser encontrada na aba Transparência, no menu do site, na categoria Projetos. O Tribunal não possui uma página dedicada para reunir os programas, porém, é possível verificar a lista e acessar todas as informações através do menu mencionado anteriormente.

Figura 5 - Programas e Ações TJ-SP

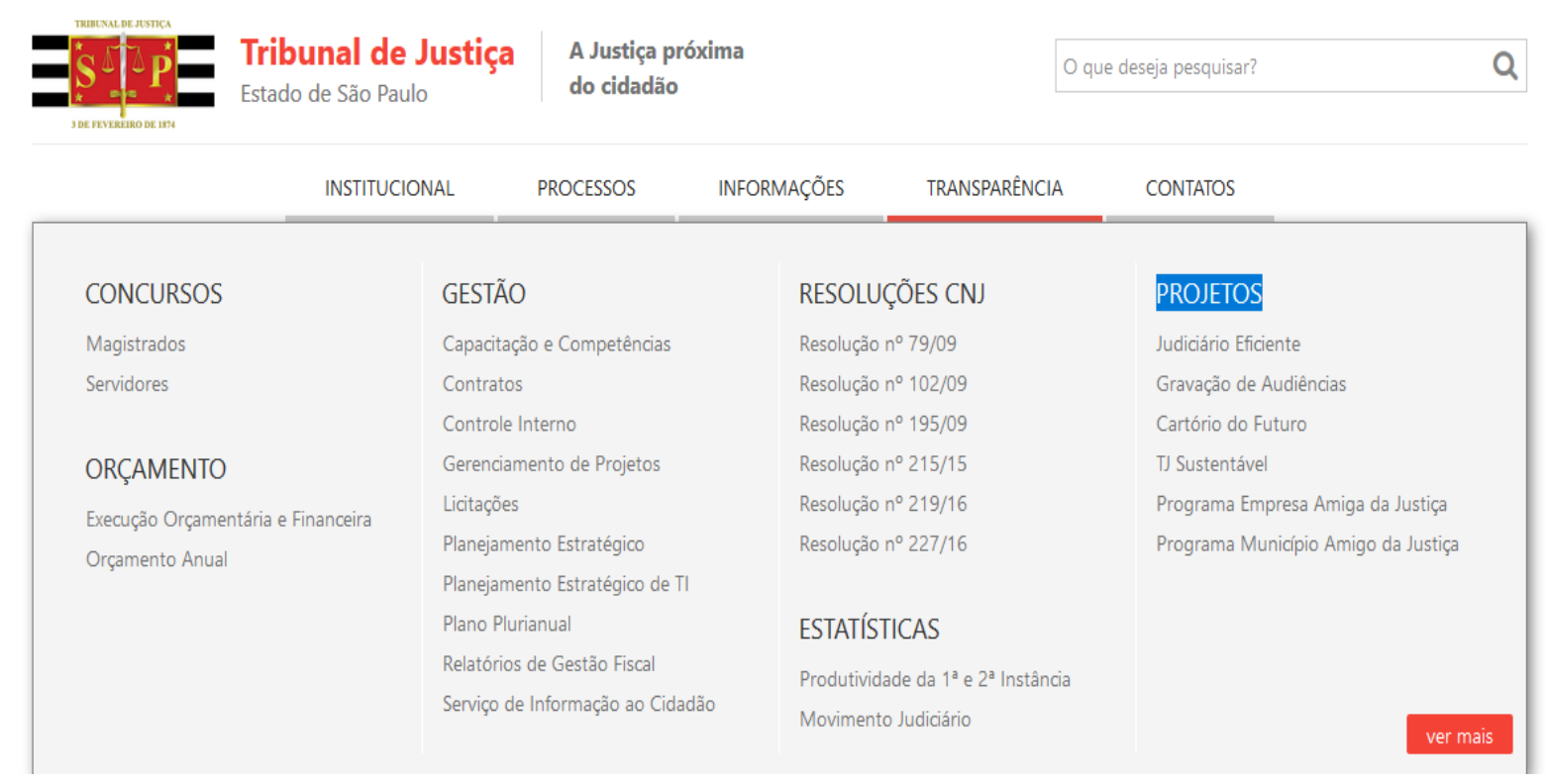

Fonte: TRIBUNAL de Justiça do Estado de São Paulo. Disponível em: http://www.tjsp.jus.br/_Acesso em 9 nov. 2018. 
Referente ao TJ de médio porte, no Tribunal de Justiça da Bahia, os programas e ações também podem ser encontrados com facilidade. No menu lateral do site, basta clicar na opção Programas e Ações para abrir um submenu que dá acesso aos links de todas as atividades produzidas pelo Tribunal.

Figura 6 - Programas e Ações TJ-BA

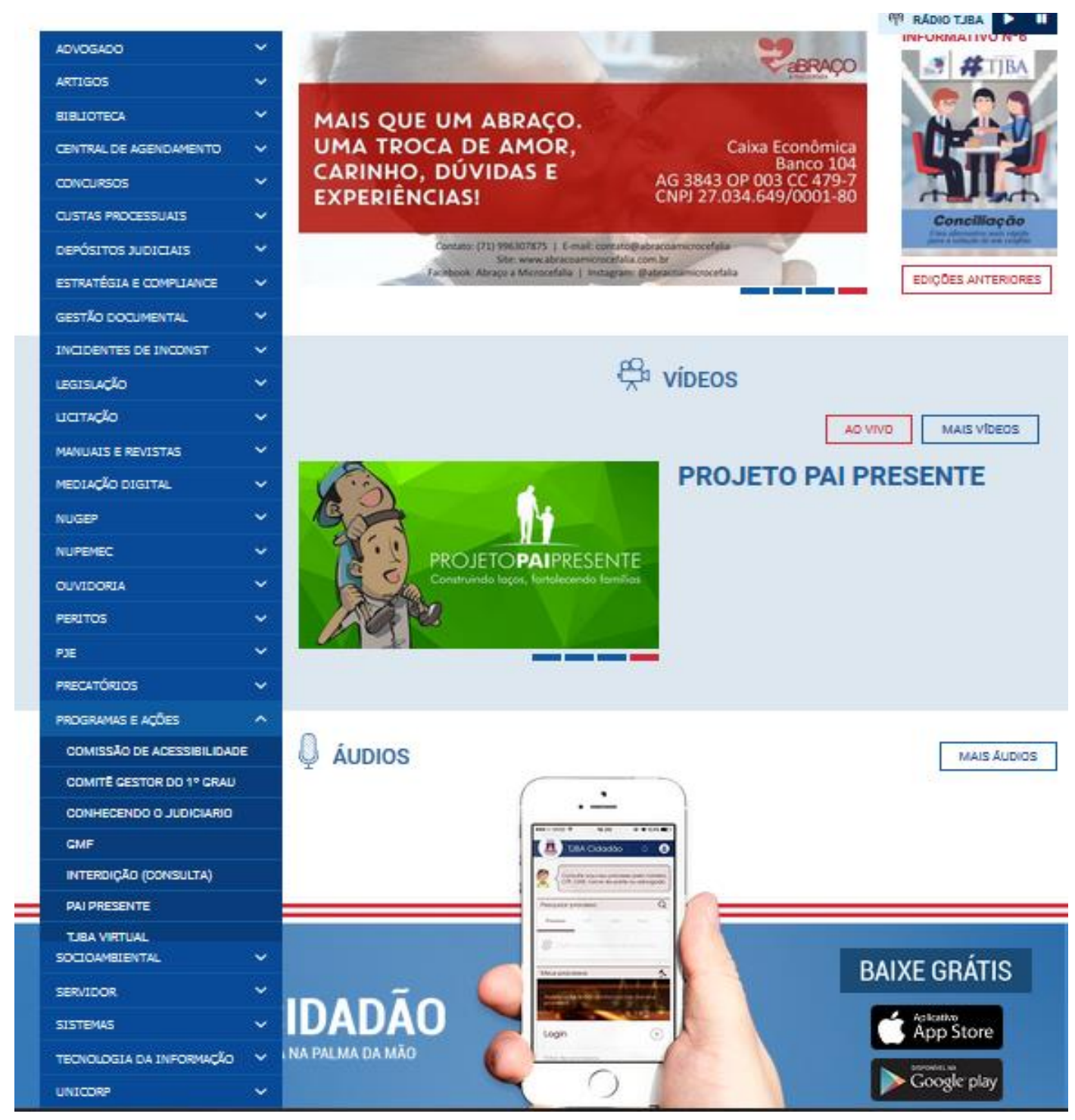

Fonte: TRIBUNAL de Justiça do Estado da Bahia. Disponível em: http://www5.tjba.jus.br/portal/. Acesso em 22 out. 2018. 
Finalizando, com o TJ de pequeno porte. No TJ-MS os programas e ações ofertados pelo Tribunal de Justiça podem ser visualizados no menu lateral da página inicial. Ao clicar na opção, é aberto um submenu com a lista dos links para cada projeto desenvolvido. Porém, por diversas vezes não foi possível acessar o submenu, o ponteiro passava pela opção, mas não existia resposta. Assim, para visualizar a lista de programas e ações, a melhor opção foi acessá-los através dos links disponíveis no rodapé da página.

Figura 7 - Programas e Ações TJ-MS 1

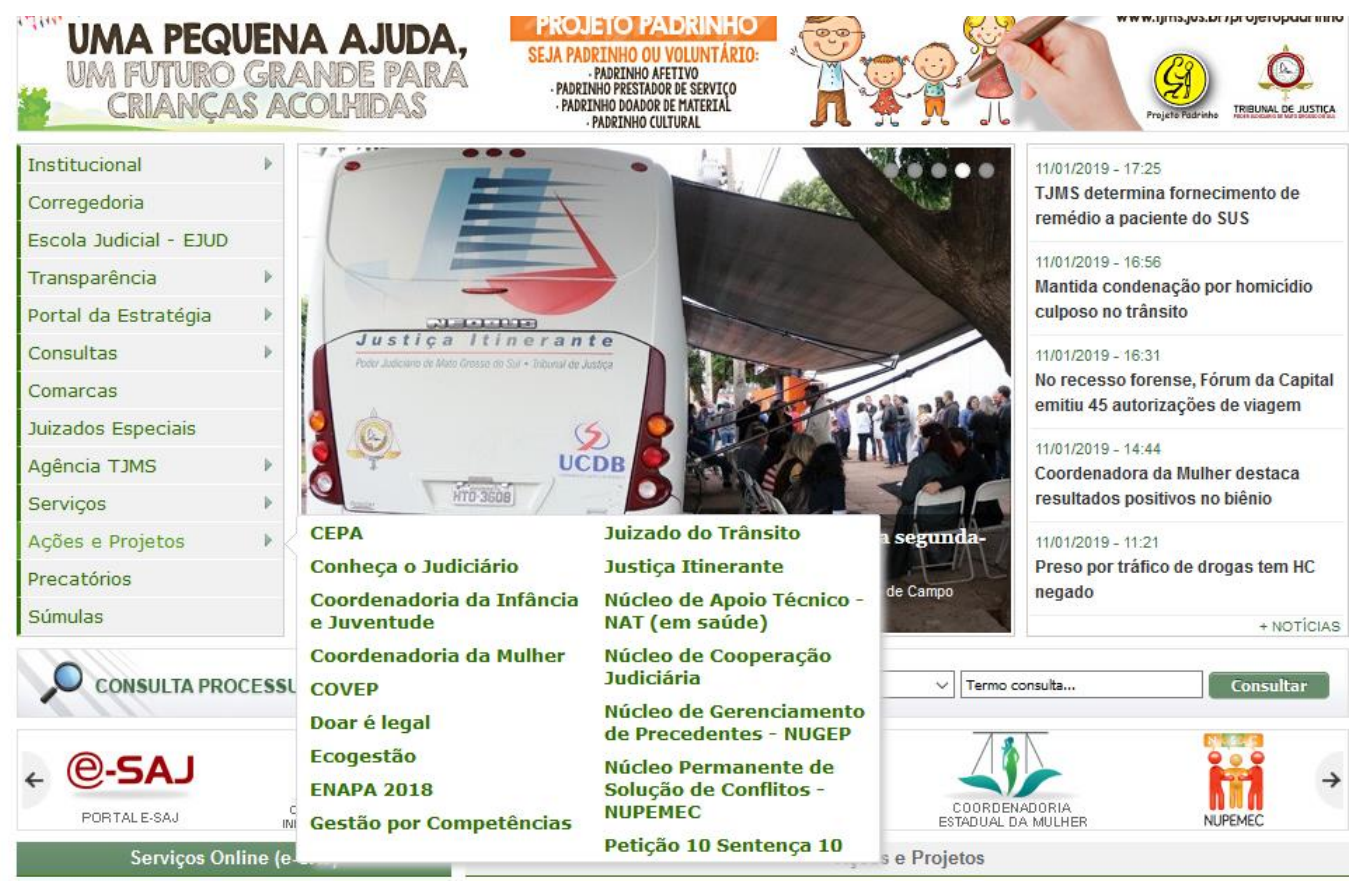

Fonte: TRIBUNAL de Justiça do Estado do Mato Grosso do Sul. Disponível em: http://www.tjms.jus.br/. Acesso em 9 nov. 2018. 
Figura 8 - Programas e Ações TJ-MS 2

\begin{tabular}{|c|c|c|c|}
\hline 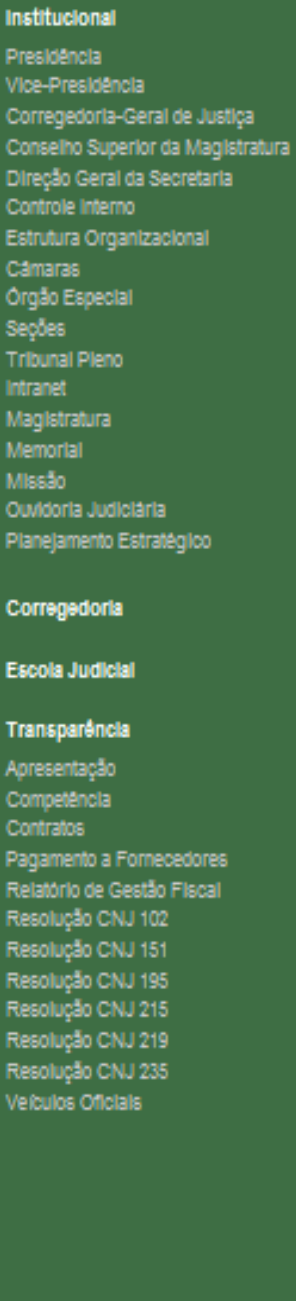 & 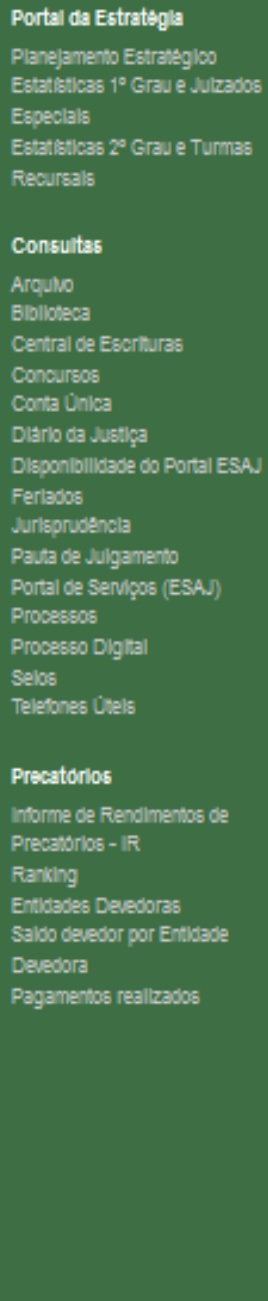 & 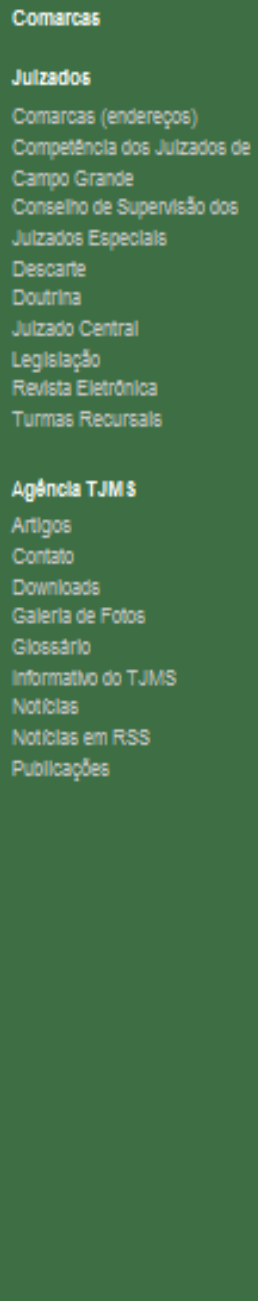 & 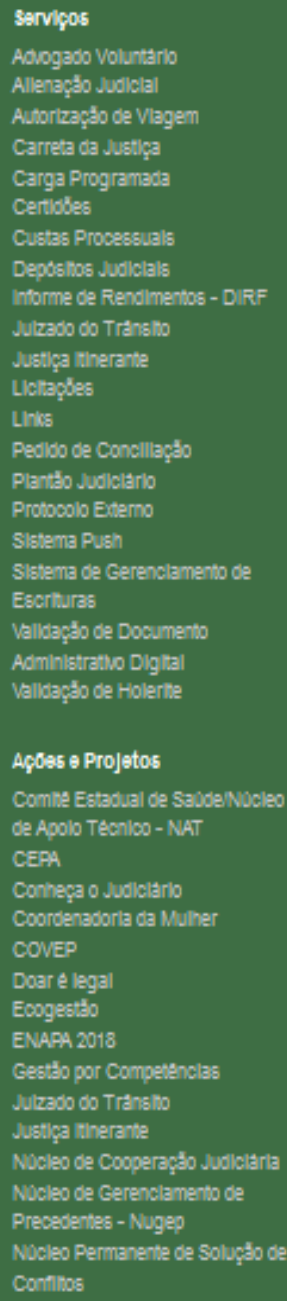 \\
\hline Fon & $\begin{array}{r}\text { Melo Gros60 - Blo00 } 13 \text { - } \\
\text { Grande - Fone: (67) } 3317- \\
\text { Hordr }\end{array}$ & ta: $12 n$ as $19 \mathrm{l}$. & $\begin{array}{l}\text { - Campo Grande - MS } \\
3317-8600\end{array}$ \\
\hline
\end{tabular}

Fonte: TRIBUNAL de Justiça do Estado do Mato Grosso do Sul. Disponível em: http://www.tjms.jus.br/. Acesso em 9 nov. 2018.

\subsection{Despesas}

Nesta categoria, os Tribunais devemf azer referência a valores pagos, a data do pagamento dessas despesas, objeto de despesa, entidade fornecedora e sua documentação (CPF ou CNPJ), além do número de processo da despesa.

Iniciando pelo Tribunal de grande porte, no TJ-SP as informações de Despesas são superficiais. A instituição disponibiliza um documento em formato PDF onde lista apenas o tipo de despesa e o valor por mês. Além disso, a informação não é de fácil acesso. $\mathrm{Na}$ aba Transparência do menu não existe um link direto para despesas, é necessário acessar a opção Execução Orçamentária e Financeira na categoria Orçamento. 
Figura 9 - despesas TJ-SP

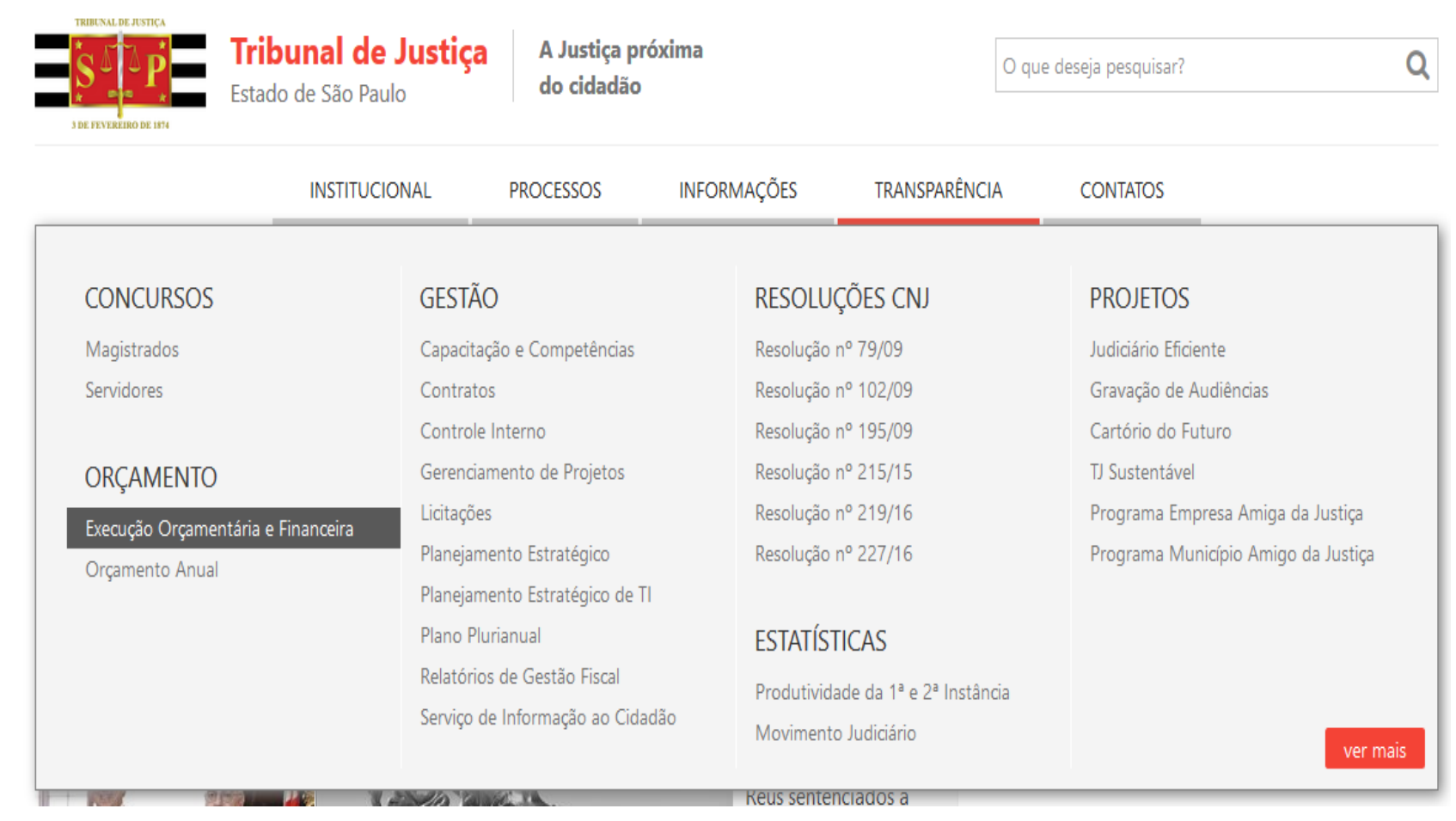

Fonte: TRIBUNAL de Justiça do Estado de São Paulo. Disponível em: http://www.tjsp.jus.br/. Acesso em 9 nov. 2018.

Diferentemente do TJ-SP, não foi possível encontrar informações sobre despesas no Tribunal de Justiça da Bahia - TJ de médio porte. Foi navegado pelas páginas, porém foram encontrados apenas relatórios de orçamento do Tribunal, além de questões fiscais. Ta mbém foi realizada uma consulta através do mecanismo de busca do portal, sem resultados.

No caso do Tribunal de Justiça de pequeno porte, a publicaçãodas informações referentes às despesas em formato de arquivo PDF também foi constatada no Tribunal de Ju stiça de Mato Grosso do Sul. As informações são disponibilizadas na página Pagamento de Fornecedores, que pode ser acessada ao clicar na opção Transparência, no menu do portal. 
Figura 10 - Despesas TJ-MS

\begin{tabular}{|c|c|c|c|c|c|c|}
\hline $\begin{array}{l}\text { UG Pagadora } \\
\text { Código }\end{array}$ & Data Pagamento & UG/CPF/CNPJ Favorecido & UG/CPF/CNPJ Favorecido Nome & Finalidade & Valor & $\begin{array}{c}\text { Valor } \\
\text { Est/Dev }\end{array}$ \\
\hline 50901 & $05 / 11 / 2018$ & $03.119 .724 / 0001-47$ & CORREIO DO ESTADO S.A. & $\{031635\} 77705-24 / 05 / 2018 \mathrm{PrC}: 158.0503 / 2018$ & 598,00 & 0,00 \\
\hline 50901 & $05 / 11 / 2018$ & $03.501 .509 / 0001-06$ & PREFETIURA MUNICIPAL DE CAMPO GRANDE MS & 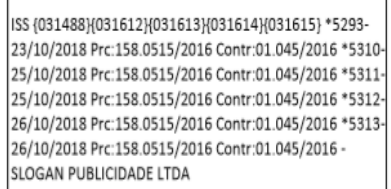 & 156,99 & 0,00 \\
\hline 50901 & $05 / 11 / 2018$ & $03.501 .509 / 0001.06$ & PREFEITURA MUNICIPAL DE CAMPO GRANDE MS & 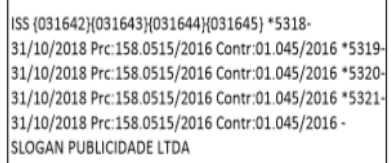 & 115,34 & 0,00 \\
\hline 50901 & 05/11/2018 & $15.545 .288 / 0001-57$ & SLOGAN PUBLICIDADE LTDA & 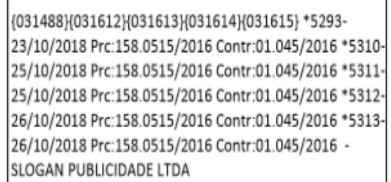 & $18.961,01$ & 0,00 \\
\hline 50901 & $05 / 11 / 2018$ & $15.545 .288 / 0001-57$ & SLOGAN PUBUICIDADE LTDA & 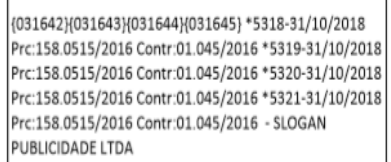 & $11.991,66$ & 0,00 \\
\hline 50901 & $05 / 11 / 2018$ & $61.600 .839 / 0001-55$ & CENTRO DE INTEGRACAO EMPRESA ESCOLA-CIEE & $\begin{array}{l}\text { 1031662) 770-01/11/2018 Ref:10/2018 } \\
\text { Pre:158.0200/2017 Contr:01.028/2017 - CENTRO DE } \\
\text { INTEGRACAO EMPRESA ESCOLA-CIEE }\end{array}$ & $729.385,57$ & 0,00 \\
\hline 50901 & $05 / 11 / 2018$ & $15.717 .139 / 0001-28$ & PAULO HENRIQUE PEREIRA DA ROCHA & $\begin{array}{l}\text { 1031626) 34-24/10/2018 PrC:158.0807/2018 - PAULO } \\
\text { HENRIQUE PEREIRA DA ROCHA }\end{array}$ & $2.300,00$ & 0,00 \\
\hline
\end{tabular}

Fonte: TRIBUNAL de Justiça do Estado de Mato Grosso do Sul. Disponível em: http://www.tjms.jus.br/transparencia/pagamento_fornecedores.php. Acesso em 9 nov. 2018.

\subsection{Licitações e contratos}

De acordo com esta dimensão, os Tribunais devem disponibilizar os valores das licitações, a data da última publicação do edital, objeto, modalidade, referência ou link com informações, além de um termo ou projeto.

Referente ao TJ de grande porte, como o caso do TJ-SP, as licitações e contratos do Tribunal podem ser encontradas facilmente na aba Transparência. Os contratos, além disso, podem ser acessados também por um link na página de licitações. Ambos os itens podem ser buscados através de uma plataforma que possibilita a busca por diversos filtros, como ano, modalidade, fornecedor, entre outros. 
Figura 11 - Licitações e Contratos TJ-SP

\section{Consulta completa}

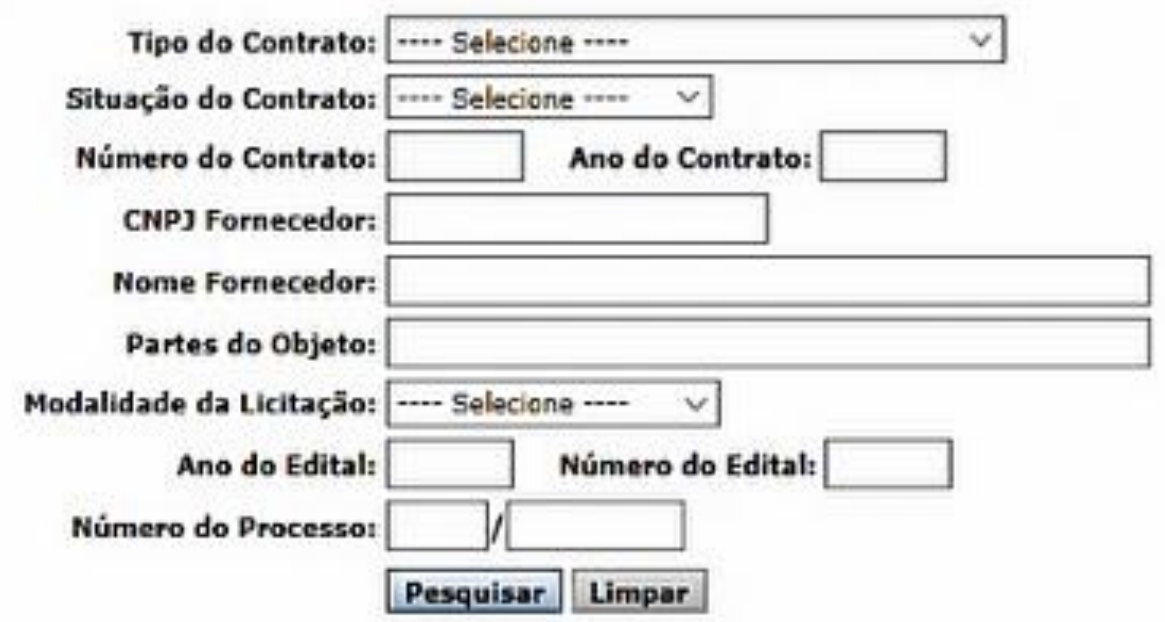

Desenvolvido pela Softpla

Fonte: TRIBUNAL de Justiça do Estado de São Paulo. Disponível em: http://www.tjsp.jus.br/portalscl/consultarLicitacaoEdital.do ?onLoad=true. Acesso em 9 nov. 2018.

Da mesma formaque no TJ anterior, tambémé possível encontrar facilmente informações sobre licitações no portal do Tribunal de Justiça da Bahia - TJ de médio porte. O site disponibiliza a opção Licitações em seu menu lateral. Ao clicar na categoria, é aberto um submenu com links para atas, pregão eletrônico, pesquisa, entre outros. Na página Pesquisa, pode ser visualizada a lista de licitações, além de realizar buscas avançadas. Porém, para o acesso aos editais, o portal exige que o cidadão preencha um campo com informações pessoais. 
Figura 12 - Licitações e Contratos TJ-BA

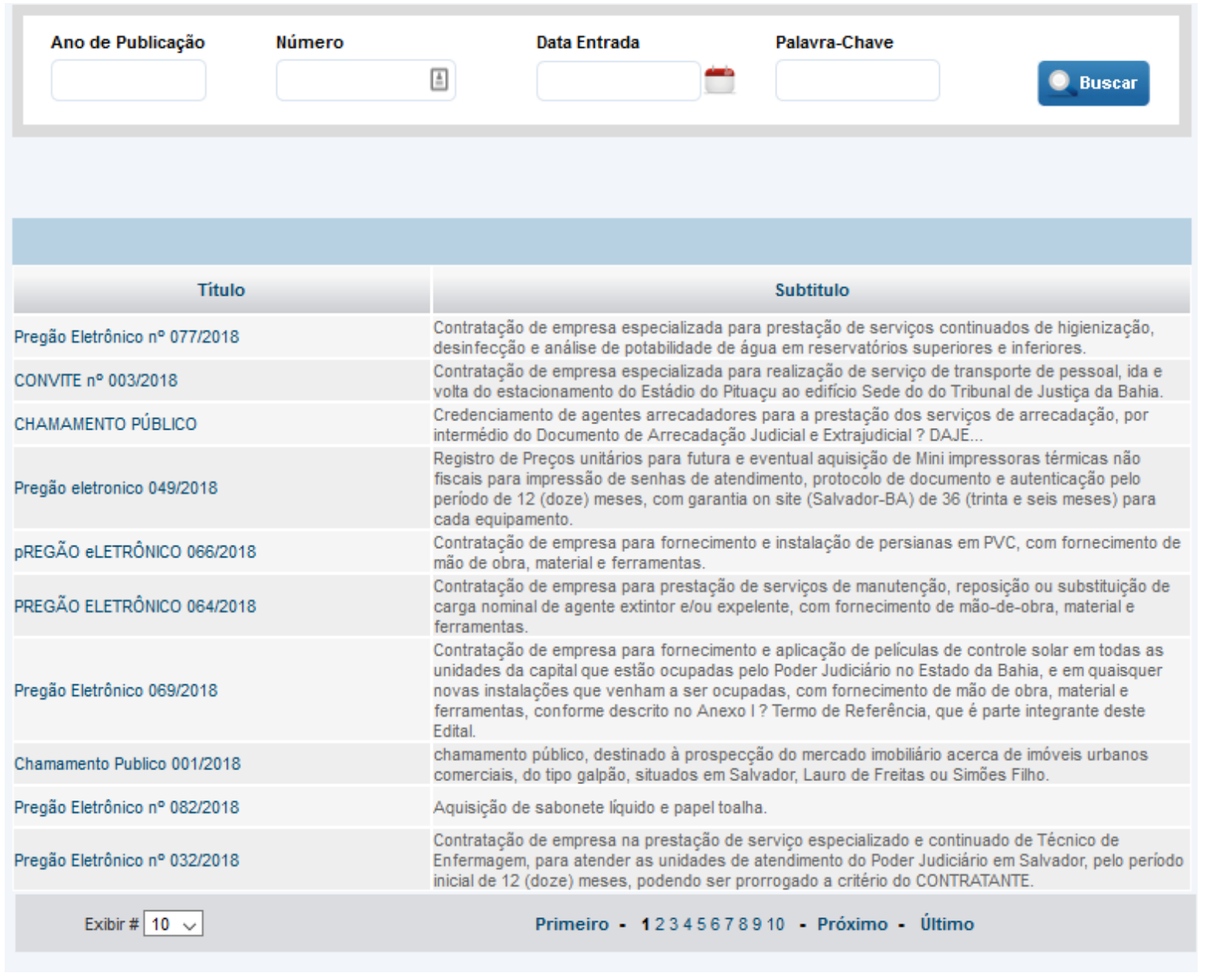

Fonte: TRIBUNAL de Justiça do Estado da Bahia. Disponível em: http://www7.tj.ba.gov.br/secao/publicacao.wsp?tmp.secao=1. Acesso em 22 out. 2018.

No Tribunal de Justiça de Mato Grosso do Sul - de pequeno porte, as licitações podem ser acessadas através de um link na aba Serviços do menu lateral. O portal permite que sejam realizadas buscas avançadas por licitações. Porém, para ter acesso às informações sobre as empresas, é necessário o preenchimento de cadastro com informações pessoais. Além disso, na lista de licitações não é possível verificar os valores. Um aspecto interessante é que várias etapas do processo podem ser verificadas através de documentos PDF, desde os editais, passando por emails com o sorteio de fiscais até o documento de homologação do processo licitatório. 
Figura 13 - Licitações e Contratos TJ-MS



Fonte: TRIBUNAL de Justiça do Estado do Mato Grosso do Sul. Disponível em:

http://www.tjms.jus.br/licitacoes/editais.php. Acesso em 9 nov. 2018.

\subsection{Questões judiciais}

Os Tribunais devem disponibilizar informações sobre sentenças, regulamentos, além de estatísticas de causas ingressadas, solucionadas e pendentes, e a publicação de agendamento de audiências.

Iniciando pelo TJ de grande porte, nessa categoria o TJ-SP disponibiliza a consulta de processos de maneira rápida, em sua página inicial, porém é necessário digitar o número do processo desejado. Entretanto existe também na página inicial um link para uma plataforma de busca avançada, onde é possível utilizar filtros como termos, vara, magistrado, data, número do processo, entre outros. 
Figura 14 - Questões Judicia is TJ-SP 1

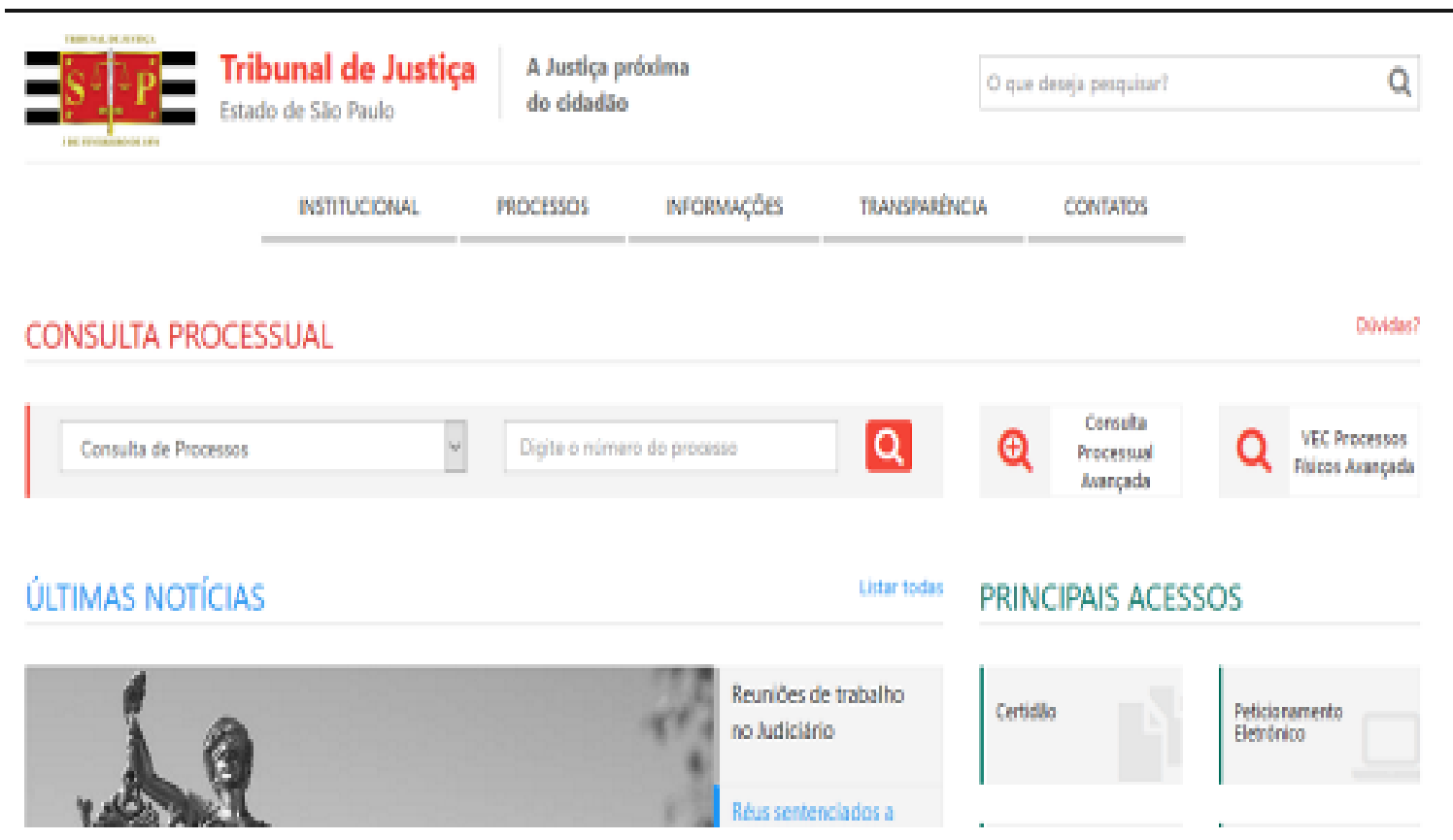

Fonte: TRIBUNAL de Justiça do Estado de São Paulo. Disponível em: http://www.tjsp.jus.br/. Acesso em 9 nov. 2018.

Assim como no TJ anterior, o TJ de médio porte aplica restrições. O Tribunal de Justiça da Bahia permite a consulta de processos desde que o internauta possua informações preliminares. Também é possível acessar informações sobre a produtividade do TJ, além de realizar agendamentos online.

Figura 15 - Questões Judicia is TJ-BA

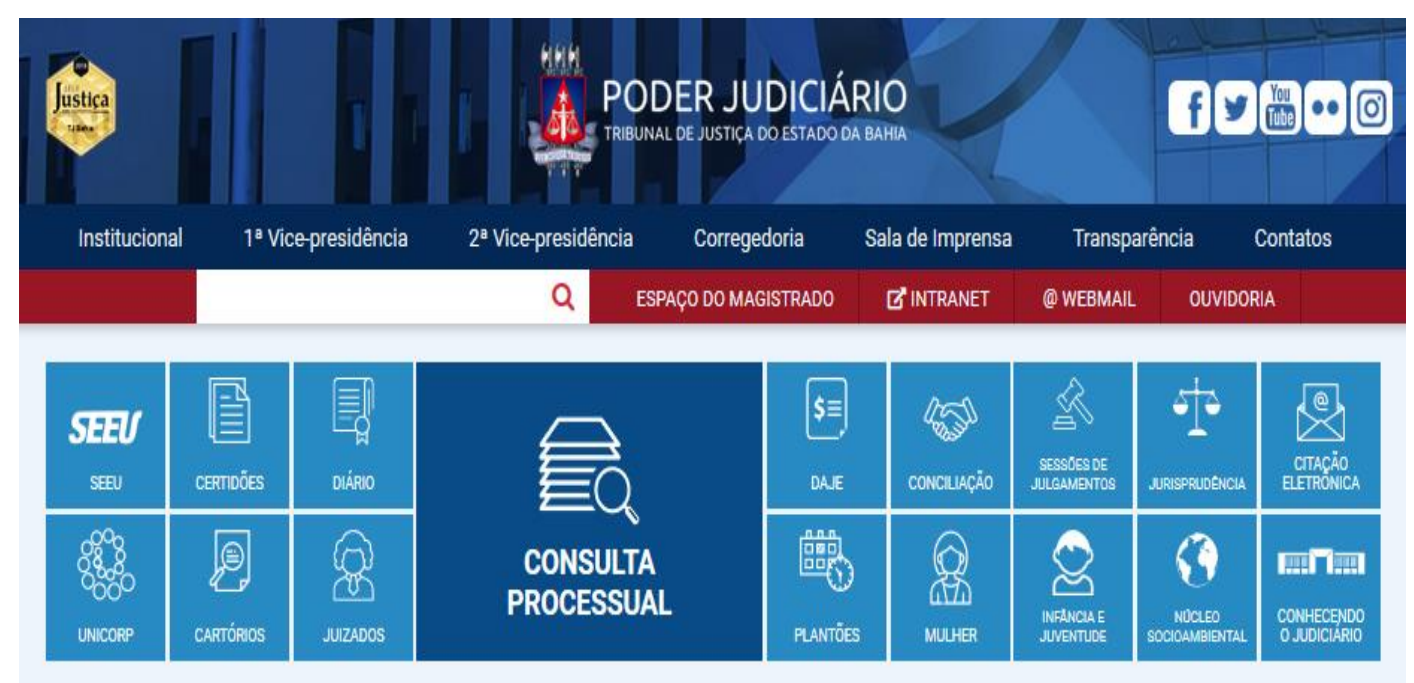

Fonte: TRIBUNAL de Justiça do Estado da Bahia. Disponível em: http://www5.tjba.jus.br/portal/. Acesso em 22 out. 2018. 
Transparência digital no Poder Judiciário brasileiro: um panorama da aplicação do acesso à informação nos tribunais de justiça

Outro que possui informações sobre a agenda de pautas é o Tribunal de Justiça de Mato Grosso do Sul - de pequeno porte. O TJ-MS permite consultas processuais online. Porém, não oferece dados de produtividade do judiciário.

Figura 16 - Questões Judicia is TJ-MS

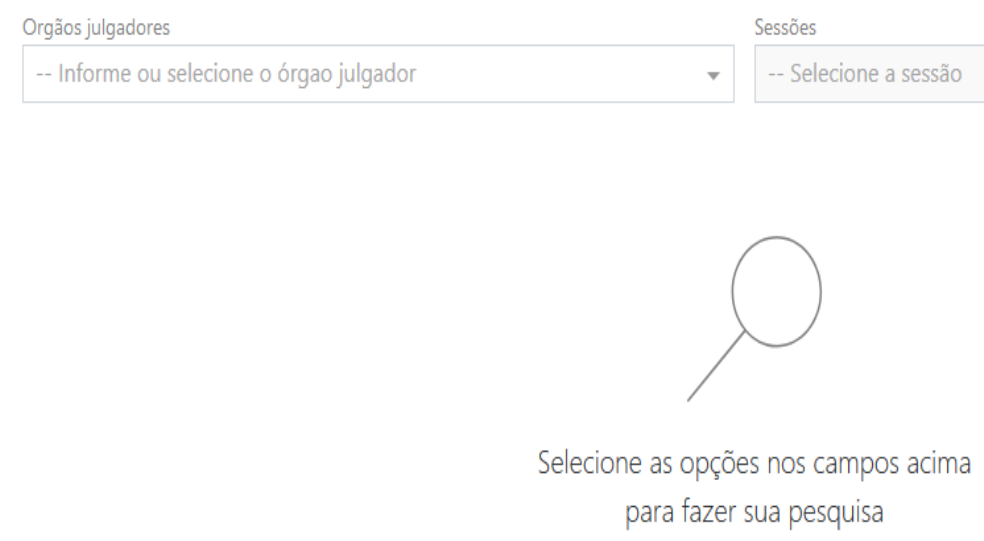

Fonte: TRIBUNAL de Justiça do Estado do Mato Grosso do Sul. Disponível em: https://esaj.tjms.jus.br/pautajulgamento/consulta. Acesso em 9 nov. 2018.

\subsection{Discussão dos achados}

Através da coleta e análise do material relacionado à transparência no site de cada um dos três Tribunais de Justiça selecionados, foi possível verificar como a transparência é aplicada em cada portal.

Entretanto, cabe dizer que a forma como a transparência é aplicad a diverge entre os Tribunais analisados. Alguns TJ oferecem mais ou menos recursos em comparação com outros, bem como a apresentação das informações têm divergências. De tal modo, essa diferença pode ter relação com diferentes organizações estruturais internas.

Outro ponto interessante é a forma de apresentação das informações e como chegar até elas. No caso de informações como endereço, telefone e horário de funcionamento, todos os sites disponibilizam por padrão ao final da página. Todavia, as informações que são apresentadas divergem entre os TJ, alguns deles não disponibilizam o número de telefone, outros não 
apresentam o horário de funcionamento. Além disso, cada Tribunal dispõe os caminhos para acesso às informações referentes à tran sparência de formas próprias. Existem casos em que links para licitações e ações estão visíveis já na página inicial do site; em outros, é necessário acessar menus específicos, como institucional, administrativo ou Transparência.

Tais diferenças na apresentação dos sites de cada um dos Tribunais reforça a importância da comunicação pública para aprimorar a comunicação entre Estado e sociedade. Afinal, para uma transparência efetiva, é preciso que exista uma comunicação de qualidade por parte do Poder Público. Esses fatos vão ao encontro da fala de Kunsch (2012), quando diz que é preciso ultrapassar barreiras burocráticas parachegar ao cidadão, e isso passa pela utilizaçãoeficiente das ferramentas digitais.

É lógico que o processo de aprimoramento nãoé algo simples, masos Tribunais precisam corrigir suas falhas e aprimorar ainda mais aquilo que já é eficiente. Afinal, como mencionado por Weber (2017), é necessário planejamento e organização para desenvolver a comunicação pública que possui um papel político e estratégico.

Além do mais, é perceptível que a transparência digital supre questões relacionadas à transparência nos Tribunais de Justiça, possibilitando maior acompanhamento e fiscalização do Judiciário através de diferentes ferramentas, permitindo acessar despesas, lic itaçõesou até mesmo trâmites jurídicos - mesmo que esses sejam restritos apenas às partes interessadas.

Entretanto, nãobasta apenas disponibilizar a informação, é necessário que ela seja de fácil acesso e compreensão, algo que por vezes não foi constata do nos sites analisados. Portanto, é fundamental que as instituições trabalhem no constante aprimoramento de suas ferramentas de transparência.

Questões relacionadas diretamente ao Judiciário devem ter maior transparência, como por exemplo, dadosestatísticos com tempo de julgamento, tipos de processo, quantidade de processos por magistrado, entre outros dados que possam ser divulgados. Podemos citar o caso do TJ-RJ como exemplo ao divulgar informações desse tipo, porém é algo pouco difundido nos demais sites. Outra função que poderia ser pensada é referente a trâmites processuais, ou seja, disponibilizar ao cidadão informações e ferramentas que auxiliem e facilitem questões burocráticas que envolvem o campo jurídico.

Tais atitudes poderiam colaborar para u ma maior abertura do Poder Judiciário brasileiro, democratizando e legitimando essa esfera de poder perante a sociedade, assim, fortalecendo sua independência através de uma política de transparência cada vez mais efetiva. Pois, como dito por Steytler (2005), os fundamentos para a integridade judicial e que são essenciais para o funcionamento de uma democracia são a independência, a imparcialidade, a responsabilidade e a transparência.

Uma análise mais ampla entre os Tribunais de Justiça pode ser vista em Schlindwein 
(2019) onde, além dos TJs mencionados neste artigo, foram analisados outros seis Tribunais e elaborado um índice de transparência aplicada pelos nove TJs, sendo três de cada porte - grande, médio e pequeno.

\section{Considerações Finais}

Esse artigo teve como objetivo analisar como os Tribunais de Justiça utilizam as ferramentas online para a aplicação da transparência ativa em seus sites. A proposta foi a de analisar como a transparência é empregada nos portais de três Tribunais de Justiça: São Paulo, Bahia e Mato Grosso do Sul.

A escolha de três Tribunais de diferentes portes (grande, médio e pequeno), foi com base nos três maiores orçamentos de cada. Assim, foi possível verificar a estrutura de Tribunais com orçamentos diferenciados.

Para a coleta do material relacionado à transparência, foi utilizada a navegação orientada, método utilizado por Almada (2013; 2017) e Amorim (2012). Desse modo, com o material coletado, o trabalho buscou comparar a estrutura de acesso à informação disponibilizada nos três portais e verificar as diferenças da aplicação da transparência ativa entre eles.

Foi constatado que os Tribunais de Justiça analisados cumprem com os requisitos básicos de transparência ativa, exceção ao TJ da Bahia que não disponibiliza informações sobre despesas em seu portal. Porém, cada um deles possui peculiaridades na aplicação da transparência, tornando o modo de acesso à informação distinto entre eles.

Nos itens relacionados à estrutura organizacional, por exemplo, o Tribunal de Justiça de São Paulo não informa em seu portal o horário de funcionamento do tribunal. O fato mostra, de certo modo, uma omissão de uma informação importante para o cidadão e que deveria estar disponível no portal da instituição. Afinal, é necessário que o Poder Público utilize os meios de comunicação para uma maior aproximação e diálogo com a sociedade. Como afirma Kunsch (2012), é necessário utilizar os meios de comunicação para informar e fomentar a comunicação pública.

Outro ponto importante é relacionado à disponibilização de informações fiscais, relacionadas a despesas e licitações. É necessário que os Tribunais de Justiça facilitem ainda mais o acesso a esse tipo de informação.

A disponibilização desse tipo de informação, além de cumprir com as questões legais, auxilia na percepção de uma boa gestão e no combate à corrupção. Afinal, a transparência auxilia no combate à corrupção através da prestação de contas (BERTOT; JAEGER; GRIMES, 2010; MICHENER; BERSCH, 2013).

Porém, como podemos constatar ao analisar a disponibilização de informações processuais pelos Tribunais de Justiça, existem aspectos que acabam conflitando com a 
publicidade da informação pública. Para o acesso aos processos, era necessário o preenchimento de informações preliminares sobre a informação que era buscada. Tal fato ocorre, pois, muitas vezes, são informações privadas que constam nos processos, ou até mesmo casos que, devido a sua natureza, correm em segredo de justiça. Portan to, apenas aqueles diretamente interessados por aquela informação podem ter acesso.

A situação vai ao encontro das afirmações de Heald (2006) e Bentham (2009), ao mencionar que a transparência pode ser limitada em algumas ocasiões, seja para preservar o sigilo de determinadas informações ou por limites no custo de sua implementação e que a publicidade dos fatos deve ser colocada de lado se prejudicar desnecessariamente pessoas inocentes ou for prevista por lei.

Através da análise, também foi possível verificar a importância da Transparência Digital para o incremento democrático. Com o auxílio das ferramentas digitais, é possível disponibilizar informações e serviços antes restritos aos ambientes físicos, ou seja, para consultar processos não é necessário o deslocamento até o fórum, basta realizar a verificação através da internet. Também não é preciso se deslocar e elaborar pedidos de acesso para a análise de questões orçamentárias de um Tribunal, os dados podem ser consultados online.

Essas são questões que colaboram para o fortalecimento democrático, afinal, com maior facilidade em obter determinadas informações, o cidadão tem condições para exercer maior participação no ambiente público, seja utilizando os dados para fiscalizar ou para debater com atores políticos e a sociedade.

\section{Referências}

ALMADA, M. P. Participação política e transparência online: um panorama sobre a democracia digital no Brasil a partir de iniciativas da sociedade civil. 2013. 176 f. Dissertação (Mestrado) Universidade Federal da Bahia, Faculdade de Comunicação, Programa de PósGraduação em Comunicação e Cultura Contemporânea, Salvador, 2013.

ALMADA, M. P. Avaliação da E-Transparência em Portais de Governos Nacionais: uma comparação entre Brasil, Estados Unidos e Reino Unido. 2017. 263 f. Tese (Doutorado) Universidade Federal da Bahia, Faculdade de Comunicação, Programa de Pós-Graduação em Comunicação e Cultura Contemporânea, Salvador, 2017.

AMORIM, P. K. D. F. Democracia e Internet: a transparência de gestão nos portais eletrônicos das capitais brasileiras. 2012. 347 f. Tese (Doutorado) Universidade Federal da Bahia, Faculdade de Comunicação, Programa de Pós-Graduação em Comunicação e Cultura Contemporânea, Salvador, 2012.

ANGÉLICO, F. et al. Desafios da transparência no Sistema de Justiça brasileiro. ed 2. São Paulo. Artigo19. 2017. Disponível em http://www.forumglobal.de/docs/Transparencia_no_Sistema_de_Justica_do_Brasil_2ed_com_entrevistas.pdf Acesso em 11 set. 2018.

BENTHAM, J. Da publicidade. Revista Brasileira de Ciência Política, v. 1, n. 6. Brasília, p. 277-294. 2011.

BERTOT, J. C.; JAEGER, P. T.; GRIMES, J. M. Using ICTs to create a culture of transparency: 
E-government and social media as openness and anti-corruption tools for societies. Government Information Quarterly, v. 27, n. 3, p. 264-271, 2010.

BOCHENEK, A. C.; DALAZOANA, V.; RISSETTI, V. R. Good governance e o Conselho Nacional de Justiça. Revista Direito GV, v. 9, n. 2, p. 535-554, São Paulo. 2013.

BRASIL. Constituição Federativa do Brasil 1988. Senado Federal. Brasília. 2017. Disponível em https://www2.senado.leg.br/bdsf/bitstream/handle/id/518231/CF88_Livro_EC91_2016.pdf Acesso em 12 out. 2018.

CONSELHO NACIONAL DE JUSTIÇA. Justiça em Números 2018: ano-base 2017. Conselho Nacional de Justiça. Brasília, 2018.

ELENA, S.; AQUILINO, N.; PICHÓN RIVIÉRE, A. Emerging Impacts in Open Data in the Judiciary Branches in Argentina, Chile and Uruguay, CIPPEC. Buenos Aires. 2014.

FUNDAÇÃO GETÚLIO VARGAS. Avaliação de transparência ativa. Fundação Getúlio Vargas. Rio de Janeiro. 2017. Disponível em https://transparencia.ebape.fgv.br/ptpfgv-avaliacaode-transparencia-ativa-avaliacao-de-repasses-transferencias-para-entidades-nao Acesso em 11 set. 2018.

FRAGALE FILHO, R. Courts on Screen. E-Governance and Civic Engagement. IGI Global. Hershey. 2011. p. 112-126 Disponível em: http://services.igiglobal.com/resolvedoi/resolve.aspx ?doi=10.4018/978-1-61350-083-5.ch006. Acesso em 10 ago. 2018.

GOMES, W.; AMORIM, P. K. D. F.; ALMADA, M. P. Novos desafios para a ideia de transparência pública. E-Compós, v. 21 n. 2. São Paulo, 2018. Disponível em: http://www.ecompos.org.br/e-compos/article/view/1446. Acesso em 30 jul. 2018.

HANSEN, H. K.; FLYVERBOM, M. The politics of transparency and the calibration of knowledge in the digital age. Organization, v. 22, n. 6, p. 872-889, 2015.

HEALD, D. Transparency as an Instrumental Value. Transparency: The Key to Better Governance? $\quad$ p.58-73, 2006. Disponível em: http://www.davidheald.com/publications/healdinstrumentalvalue.pdf. Acesso em: 27/9/2017

HOCH, P. A.; RIGUI, L. M.; SILVA, R. L. DA. Desafios à concretização da transparência ativa na internet, à luz da lei de acesso à informação pública: análise dos portais dos Tribunais Regionais Federais. Revista Direitos Emergentes na Sociedade Global, v. 1, n. 2, p. 257-286, Santa Maria. 2013.

KIŠKIS, M.; PETRAUSKAS, R. ICT adoption in the judiciary: classifying of judicial information. International Review of Law, Computers \& Technology, 2004

KUNSCH, M. Comunicação pública: direitos de cidadania, fundamentos e práticas, In: MATOS, H. (org.). Comunicação Pública: interlocuções, interlocutores e perspectivas. SP: ECA/USP, São Paulo, 2012.

MEIJER, A. Understanding modern transparency. International Review of Administrative Sciences, v. 75, n. 2, p. 255-269, 2009.

MICHENER, G.; BERSCH, K. Identifying transparency.Information Polity, v. 18, n. 3, p. 233 $242,2013$.

MICHENER, G. et al. Avaliação de Transparência do Estado Brasileiro e do Poder Judiciário. Rio de Janeiro: Escola de Direito do Rio de Janeiro da Fundação Getúlio Vargas, Centro de Tecnologia e Sociedade, 2016.

MICHENER, G.; NISKIER, I. Lei de Acesso à Informação faz 5 anos com avanços e limitações. Folha de São Paulo Online. Disponível em: http://www 1.folha.uol.com.br/poder/2017/09/1923133-lei-de-acesso-a-informacao-faz-5-anoscom-avancos-e-limitacoes. shtml?mobile . Acesso em: 30 set. 2017. 
OLIVEIRA, G. F.; DINARTE, P. V. O Poder Judiciário na Sociedade em Rede: A Transparência Passiva Como Nova Forma de Democratização da Justiça. Revista de Política Judiciária, Gestão e Administração da Justiça, v. 1, n. 1, p. 276-308, 6 dez. 2015.

SILVA, S. P. da. Estado, democracia e internet: requisitos democráticos e dimensões analíticas para a interface digital do Estado. 2009. 424 f. Tese (Doutorado) - Faculdade de Comunicação, Universidade Federal da Bahia, Salvador, 2009.

STEYTLER, J. C. Transparency, accountability and fighting corruption in the judiciary. Conference Paper for International Conference and Showcase on Judicial Reforms, Manila, November 2005. http://jrn21.supremecourt.gov.ph/forumicsjr/ICSJR Australia\%20(C\%20Steytler).pdf. 2005.

TAVARES, L. E.; PEREIRA, N. B. A transparência pública na era digital., v. 17. V SIMPÓSIO NACIONAL DA ASSOCIAÇÃO BRASILEIRA DE PESQUISADORES EM CIBERCULTURA. Anais... Florianópolis, Centro de Cultura e Eventos da UniversidadeFederal de Santa Catarina, 16 a 18 de novembro de 2011.

VELICOGNA, M.; NG, G. Y. Legitimacy and internet in the judiciary: A lesson from the Italian courts' websites experience. International Journal of Law and Information Technology, v. 14, n. 3, p. 370-389, 2006.

VOERMANS, W. Judicial transparency furthering public accountability for new judiciaries. Utrecht Law Review, v. 3, n. 1, p. 148-159, 2007.

WEBER, M. H. Nas redes de comunicação pública, as disputas possíveis de poder e visibilidade. In: WEBER, M. H.; COELHO, M. P.; LOCATELLI, C. Comunicação pública e política: pesquisa e práticas. Porto Alegre: Insular, 2017.

Artigo submetido em: 2020-05-21

Artigo reapresentado em: 2021-02-05

Artigo aceito em: 2021-02-22 